\title{
Las pandemias precedentes a la COVID-19: de la peste de Atenas a la peste rosa
}

\section{From the Athens's plague to the pink plague: the history of pandemics before COVID-19}

\section{As pandemias anteriores à COVID-19: da peste de Atenas à peste rosa}

\author{
Marcelo Rodríguez Ceberio, ORCID 0000-0002-4671-440X
}

\section{Universidad de Flores. Escuela Sistémica Argentina}

Resumen: Las grandes epidemias de la historia no solo ocasionaron muertes, sino crisis emocionales, psicosociales y económicas. Pero al final de cuentas la resiliencia ganó terreno, generando un gran aprendizaje y el incremento de la capacidad de adaptación y supervivencia. El presente artículo es el primero de dos, que categorizan a las grandes epidemias que azotaron al mundo en diversos períodos de la historia. Se describen sus síntomas y su etiología enmarcados en su contexto histórico. Epidemias y pandemias son el resultado de variables como la pobreza, la falta de higiene, una grave tendencia al individualismo, entre otras; además del factor de estrés, producto de un ritmo de vida acelerado, todos estos factores perviven hasta nuestros días.

Palabras clave: COVID-19; pandemia; pestes; epidemias; contexto

Abstract: In world history, great epidemics not only caused thousands of deaths, but also emotional, psychosocial and even economical crises. But in the end, resilience gained territory, causing great learning and increased capacity for adaptation and survival. This article is the first of two, which categorize the great epidemics that hit the world during various periods of history. Its symptoms and its etiology are described within the historical context. Epidemics and pandemics are the result of variables such as poverty, lack of hygiene and a serious tendency to individualism, among others; in addition to stress factors that are the result of an accelerated rhythm of life, all of which survive to this day.

Keywords: COVID-19; pandemic; plagues; epidemics; context

Resumo: Na história do mundo, as grandes epidemias não causaram apenas mortes na população, mas também crises emocionais, psicossociais e até econômicas nas pessoas que conseguiram sobreviver a tais catástrofes. Entretanto, no final, a resiliência ganhou território, gerando grande aprendizado e aumento da capacidade de adaptação e sobrevivência. Este artigo é o primeiro de dois, que categorizam as grandes epidemias que atingiram o mundo em vários períodos da história. Seus sintomas e sua etiologia são descritos dentro do contexto histórico. Epidemias e pandemias que resultam de variáveis como pobreza, falta de higiene, grave tendência ao individualismo, entre outras; além de estressores decorrentes de um ritmo de vida acelerado, que permanecem até os dias de hoje.

Palavras-chave: COVID-19; pandemia; pragas; epidemias; contexto 
Cómo citar:

Rodríguez Ceberio, M. (2021). Las pandemias precedentes a la COVID-19: de la peste de Atenas a la peste rosa. Ciencias Psicológicas, 15(1), e-2555. doi: https://doi.org/10.22235/cp.v15i1.2555

Correspondencia: Marcelo Rodríguez Ceberio. Universidad de Flores. Escuela Sistémica Argentina. E-mail: marcelorceberio@gmail.com

\section{Introducción: crisis, sociedad y pestes}

Las crisis constituyen oportunidades para crecer a pesar de que generan en los sistemas revoluciones a múltiples niveles: una gran masa de entropía que desordena el statu quo. Son definidas como un estado de máxima tensión que rompe con la estabilidad de un sistema (Ceberio \& Watzlawick, 1998).

Si bien hay crisis que siguen el libreto evolutivo de la vida, hay situaciones críticas que no son esperables: fenómenos naturales como terremotos y tsunamis, o muertes en ciclos evolutivos que no se esperan, pandemias y epidemias, accidentes, etc. (Hoffman, 1987). Por lo tanto, la pandemia y la consecuente cuarentena que estamos viviendo -así declarada por la Organización Mundial de la Salud (OMS) - es una situación que se engloba dentro del segundo grupo (Pérez Abreu, Gómez Tejeda, \& Dieguez Guach, 2020; Trilla, 2020). Tengamos en cuenta la diferencia, puesto que la crisis disruptiva primera es la pandemia en sí misma que acarrea miedo al contagio, angustia y ansiedad (Ceberio, 2020a) y la cuarentena que como método protector produce niveles ansiogénicos importantes a los que se asocia la incertidumbre (Ceberio, 2020b).

Una epidemia se refiere a cualquier enfermedad que se transmite en una población de forma activa y escapa al control socio-sanitario (de Rezende, 1998). Las pandemias históricas han sido verdaderas crisis que han devastado diferentes contextos de la humanidad, tanto es así que algunas de ellas han eliminado a más personas que las guerras mundiales (Esparza, 2016; Portal de la Historia, 2020; Villamil Jiménez, 2013). Desde la antigüedad hasta hoy han dejado una secuela de efectos que signan la construcción de una nueva historia. En la actualidad estamos en presencia y somos testigos de una de esas pandemias: la COVID-19.

\section{Las pestes mortíferas}

En ese momento, a todas las plagas se les daba el nombre de peste. En la Grecia antigua, Hipócrates (460 a. C.-370 a. C.) consideró que la peste era una enfermedad que aparecía en las estaciones cálidas y húmedas (Giménez, \& Pardo, 2018).

La peste de Atenas (430-426 a. C.) fue realmente caótica y devastó al mundo griego en todas sus dimensiones. Se cree que llegó desde Etiopía (África) a Atenas en los barcos de mercancías y de guerra. Los autores más antiguos consideraban a esta enfermedad como una afección de origen divino, que se transmitía por el aire. Las conclusiones actuales de algunas investigaciones coinciden en que puede haberse tratado de la fiebre tifoidea. El resultado de esta epidemia fue que Atenas perdiera un tercio de la población, entre ellos la infantería ateniense y expertos marinos. Pericles también murió a causa de la enfermedad (Giménez \& Pardo, 2018; Castañeda Guillot \& Ramos Serpa, 2020).

Seguidamente a la peste de Atenas, la peste de Agrigento produjo la misma sintomatología como también la de Siracusa, que sobrevino en el año 396 a. C, cuando el ejército cartaginés sitió Siracusa, en Italia. La enfermedad diezmó al ejército de soldados cartagineses (Rodríguez, 2020). Los síntomas casi idénticos a la mayoría de las "pestes" eran: fiebre, anomalías respiratorias, dolores intercostales, disentería y pústulas en todo el cuerpo. 
Roma también sufrió los embates de la peste Antonina en el siglo II, bajo el gobierno de Marco Aurelio, que fue una de sus víctimas más notables. La peste causaba halitosis y ardor en los ojos, gangrenas, producía mucha sed y quemazón interior, delirios y tos. Las personas se morían en el lapso de diez días (Marcone, 2002; Ruiz-Patiño, 2020). Esta peste se extendió por toda Italia, llegando hasta las Galias (Buora \& Jobst, 2002).

La peste justiniana toma el nombre porque el emperador Justiniano la padeció y se estima que mató a casi a 25 millones de personas en el mediterráneo. Entre los síntomas se observaban: fiebre súbita, hinchazones en axilas, músculos y los cartílagos de las orejas. Esta pandemia comenzó en el siglo VI y el epicentro del brote fue Constantinopla (Ortiz, 2020). Se cree que esta peste fue causada por una cepa de Yersinia pestis, la misma bacteria causante de la peste bubónica o peste negra, y es una mezcla de varias plagas como la peste bubónica, la viruela o el cólera. Las tres unidas fueron devastadoras, aunque es bastante difícil estimarlo (Cravioto \& García, 2013a; Rius i Gibert, 2019).

La peste negra o peste bubónica,fue la pandemia más letal de la historia y asoló principalmente a Europa. Esta afección, que había tenido su primer brote en 1347, era ya conocida en todo el mundo como la peste negra debido a las manchas pardas que aparecían a consecuencia de las hemorragias subcutáneas. Tuvo implicaciones sociales debido a la muerte de 75 millones de personas. Fue transmitida a través de las pulgas, mediante las ratas; y las ratas proliferaban en las urbes medievales en los desagües y la suciedad y basura de las calles (Callicó, 1970; Cravioto \& García, 2013b). Sintomáticamente, provocaba la inflamación de ganglios infectados en los órganos sexuales y ojos. Pero la peste bubónica apareció por tercera vez y se denominó tercera pandemia. El virus se localizó en la provincia de Yunnan en China y permaneció activo hasta 1959 y a lo largo de diez años llevó a la muerte a más de 12 millones de personas (Cravioto \& García, 2013b).

\section{Entre pulgas y mosquitos}

Muchos españoles en la conquista sufrieron la fiebre amarilla, que fue durante siglos uno de los más graves problemas de salud pública de la humanidad, aunque el desarrollo de su vacuna logró reducir la posibilidad de contagio solamente a zonas selváticas. Cabe aclarar que la enfermedad no apareció en la época de la conquista únicamente, sino que se extendió hasta el siglo XIX. La fiebre amarilla es producida por un virus de la familia Flaviviridae, el cual se transmite por la picadura de mosquitos (Restrepo, 2004). Los brotes se acrecentaban en los meses de verano y desaparecían en temporada invernal, para reaparecer con toda su fuerza al verano siguiente, aunque los que ya habían sido contagiados eran mucho más resistentes al volver a tenerla (Galeano, 2009; Restrepo, 2004).

El tifus durante siglos ha producido epidemias devastadoras y se transmite por vectores como los insectos y otros artrópodos (González-Hernández et al., 2017). La primera epidemia de tifus de la que existe constancia tuvo lugar durante el cerco de Granada por los Reyes Católicos, en 1489. Normalmente afecta a poblaciones rurales o muy aisladas debido a los vectores principales y a sus reservorios animales. Aunque el tifus ha matado a más de 4 millones de personas a lo largo de su historia, hoy no supone un peligro en el mundo moderno.

La malaria o paludismo es una enfermedad febril aguda y en la actualidad mata a más de medio millón de personas al año, principalmente en África. Gracias al pesticida DDT (dicloro difenil tricloroetano) desapareció de Europa, donde era endémica en países como Grecia o Italia. En España se pasó de 400.000 casos y más de 1.300 muertes en 1943 a desaparecer por completo en la década de los sesenta (Ceberio, 2020a). El paludismo es causado por parásitos del género Plasmodium, que se transmiten al ser humano por la picadura de mosquitos hembra del género Anopheles. Si no se trata en las primeras 24 horas puede agravarse llevando a menudo a la muerte (Pereira \& Pérez, 2002). 


\section{Los contagios en los barcos de la conquista}

La viruela es otra de las enfermedades muy contagiosas que azotó a la humanidad. Es causada por el virus Variola virus (Campillo, 2014), que trajeron los conquistadores a América cuando cruzaron el océano desde Europa. Ha llegado a tener tasas de mortalidad de hasta un $30 \%$ y se calcula que se han muerto 300 millones de personas. El brote de viruela en el siglo XVIII fue devastador, hasta que E. Jenner diseñó la primera vacuna en 1796 (Huguet Pané, 2020). La viruela está erradicada desde 1980.

El escorbuto también fue una patología que se contrajo en los viajes transoceánicos en la Edad Media. Marineros españoles y portugueses la traían en los viajes durante años. La sufrieron personajes ilustres como Vasco de Gama y Magallanes. Hasta mediados del siglo XVIII no se lo relacionó con la falta de vitamina $\mathrm{C}$ provocada por la carencia de frutas y verduras frescas en la dieta (JáureguiLobera, 2017; Rizzi, 2004).

En el Renacimiento, la sífilis fue una de las enfermedades tristemente más relevantes. Fue interpretada como un estigma que se contagiaba con los placeres carnales. El organismo que la causa es el Treponema pallidum y llegó a Europa procedente de América, se cree que se propagó por Europa tras el sitio de Nápoles en 1495, contagiada por los españoles a las prostitutas italianas. O sea, el contagio se produce por vía sexual, es transmisible a la descendencia y afecta a ambos sexos por igual y con cierta preponderancia en personas jóvenes (Leitner, Körte, Edo \& Braga, 2007).

El término sífilis fue introducido por el médico veronés Girolamo Fracastoro, quien publicó el poema Syphilis sive morbos gallicus (1530). En él describe la enfermedad y propone ese nombre en honor a un pastor de nombre Syphilo (Berdasquera Corcho, Lazo Álvarez, Galindo Santana \& Gala González, 2004; Comerio, 2012). A comienzos del siglo XX, el $15 \%$ de la población europea la padecía, entre ellos Baudelaire, Van Gogh, Nietzsche, Beethoven, Wilde, Colón, Joyce y Hitler (Comerio, 2012).

\section{Entre deformidad, el pozo de Broad Street y la peste rosa}

La lepra es una patología infecciosa y crónica producida por el bacilo Mycobacterium leprae, que afecta las mucosas, huesos, piel, testículos y los nervios periféricos. Lamentablemente los contagiados tienen una apariencia deformante e incapacita por las complicaciones neurológicas que produce. En la Edad Media se creía que los leprosos se enfermaban por un castigo de Dios, por sus pecados y sus conductas promiscuas. Con este estigma, eran abandonados fuera de los pueblos y desposeídos de sus bienes. Usaban una campanilla para anunciarse o llevaban unas pequeñas tablas en la mano para avisar a la gente de su presencia (Guerrero, Martínez, Diéguez, Arrazola \& Guzmán, 2012). Finalmente, después de cuatro siglos, en 1987, Jacinto Convit descubrió la cura para esta enfermedad (Suárez \& Lombardi, 1997).

Por otra parte, la poliomielitis se conoce desde hace tres milenios, aunque su vacuna tenga poco más de medio siglo. Es una enfermedad infectocontagiosa que afectó a gran cantidad de personas durante la primera mitad del siglo XX, siendo la epidemia más conocida la que se desarrolló en Nueva York en los años 20 y que contagiaría hasta al presidente. La poliomielitis ha sido durante siglos una importante causa de invalidez y de muerte en la infancia, hasta la llegada de la vacuna a mediados de la década de 1950 (Testa, 2012).

La pandemia del cólera llegó a Europa en 1830 y causó aproximadamente 30.000 muertes en Londres, hasta que el médico John Snow descubrió que todas ellas tenían en común el agua del pozo de Broad Street. Es una enfermedad causada por una bacteria, la Vibrio cholerae, cuya sintomatología está compuesta de fiebres y dolor abdominal, y provoca una deshidratación mortal con la que el cuerpo pierde agua debido a la diarrea. A partir del siglo XX esta enfermedad se trasladó a Asia y África, donde continúa activa (Sánchez Lera \& Pérez Vázquez, 2014). La falta de tratamiento de los excrementos humanos y la ausencia de agua potable son los principales responsables de la propagación del cólera (González Valdés, Casanova Moreno \& Pérez Labrador, 2011). 
El sarampión se considera la segunda pandemia más letal. La enfermedad se conoce desde hace más de 3.000 años y su principal problema es la alta tasa de contagio. Es una enfermedad que desarrolla manchas rojizas en todo el cuerpo, fiebres altas e inflamación pulmonar (Campillo, 2014). La forma de contagio es mediante el contacto directo y por el aire mediante las gotas de vapor que exhalamos. La muerte en el sarampión se produce por inflamación pulmonar o de las meninges. Aunque se ha controlado el contagio, el sarampión ha matado a más de 200 millones de personas y todavía no se la ha erradicado de manera definitiva, a pesar de los esfuerzos de la OMS. (Infosalus, 2020).

El VIH (Virus de Inmunodeficiencia Humana) es la pandemia que sigue teniendo vigencia en la actualidad. En 1981 se conocieron los primeros casos de esta enfermedad, que fue descubierta por Luc Montagnier en Francia, cuya sintomatología consiste en provocar una desorganización y deterioro del sistema inmunológico, logrando que la persona se vulnerabilice a cualquier enfermedad. Es decir, no es el virus en sí el que genera las consecuencias letales, sino que destruye la capacidad de defensa ante otras enfermedades comunes y corrientes, de manera que la más mínima infección puede matar (Alcamí, 2008; Swenson, 1989). La teoría más extendida es que se contrajo a partir de personas que cazaron o comieron chimpancés infectados, probablemente a finales del siglo XIX o principios del XX. Sin embargo, sigue siendo una incógnita cómo la enfermedad cruzó la barrera entre las especies.

Desde que se declararon los primeros casos de VIH, 78 millones de personas han contraído el virus y 35 millones han muerto por enfermedades relacionadas con el sida, según los datos del programa de las Naciones Unidas (Infosalus, 2020). Se transmite por la sangre y por fluidos corporales. Si bien este virus no tiene cura, en la década de 1990 se desarrollaron fármacos que como parte de diversos tratamientos y conjuntamente con la modificación del estilo de vida hacen que la enfermedad se detenga y pueda ser controlada. Solo el $50 \%$ de la población del mundo que vive con VIH recibe un tratamiento antirretroviral. Por tal razón, el sida continúa siendo un desafío para la ciencia mundial y cada año se sigue investigando para tratar de acabar con esta enfermedad. Por el momento, solo dos personas han conseguido ser curadas, pero es un gran avance que da esperanzas a futuro (Grmek, 1992; Swenson, 1989).

\section{Conclusión: contexto y epidemias}

Este primer recorrido histórico ha estado marcado por devastadoras epidemias que ocasionaron millones de muertos. En los diferentes contextos, desde la Grecia antigua con la peste de Atenas, el medioevo, las conquistas y la sífilis, hasta la posmodernidad y el VIH, las enfermedades se asociaron con muerte, desahucio y depresión.

No se trata solamente de la enfermedad y el contagio, los métodos preventivos, la higiene y la asepsia, o la cuarentena, sino que hay otras emociones que circundan a la pandemia. En una pandemia inciden el dolor, la angustia, los síntomas físicos insoportables -con medicamentos paliativos escasos-, así como la hecatombe social y económica, que llevan a la redefinición de loa valores y el estilo de vida, mitos que se derrumban, creación de nuevos trabajos y hasta nuevas formas de relación social.

Las muertes crearon depresión, duelos que acarrearon ansiedades y tristezas, familias que se desmembraron. También han generado políticas sanitarias de emergencia, avances científicos con respecto a diversas enfermedades, planes de prevención y modelos de tratamiento. Es decir, las grandes pandemias como crisis han tenido su coletazo social, cultural, político y económico, generando oportunidades de modificaciones que llegan hasta nuestros días.

Todos estos desarrollos entrópicos en cada pandemia llevan su contrapartida. Los factores de solidaridad, atención, afecto y mancomunión social son algunos de los resultados que demarcan una actitud resiliente. Con lo cual, lo aprendido en cada situación crítica se aplica en futuras situaciones, 
como de hecho se observan en nuestros días con la pandemia de la COVID-19, cuyos antecedentes, el SARS y el MERS, favorecieron a la organización de la situación de emergencia.

\section{Referencias}

Alcamí, J. (2008). Introducción. Una breve historia del sida. Enfermedades Infecciosas y Microbiología Clínica, 26, 1-4. doi: https://doi.org/10.1016/S0213-005X(08)76556-X

Berdasquera Corcho, D., Lazo Álvarez, M. Á., Galindo Santana, B. M., \& Gala González, A. (2004). Sífilis: pasado y presente. Revista Cubana de Higiene y Epidemiología, 42(2), 0-0.

Buora, M., \& Jobst, W. (Eds.). (2002). Roma sul Danubio: da Aquileia a Carnuntum lungo la via dell'ambra (Vol. 6). L'Erma di Bretschneider.

Callicó, J. S. (1970). La peste negra en la península Ibérica. Anuario de estudios medievales, 7, 67.

Campillo, S. (2014). Las 10 pandemias más letales en la historia de la humanidad. Recuperado de www.hipertextual.com

Castañeda Guillot, C., \& Ramos Serpa, G. (2020). Principales pandemias en la historia de la humanidad. Revista Cubana de Pediatría, 92(Suppl.), e-1183.

Ceberio, M. R. \& Watzlawick P. (1998). La construcción del Universo. Barcelona: Herder.

Ceberio, M. R. (2020a). Las pandemias históricas ¿lograron cambiar la filosofía de vida? Diario ABC 28/04/2020. Recuperado de https://www.abc.com.py/opinion/2020/04/28/

Ceberio, M. R. (2020b). Barbijos emocionales. Buenos Aires: Akadia

Comerio, C. (2012). La historia de la sífilis o ¿la sífilis en la historia? Revista Médica Universitaria, $8(1)$.

Cravioto, E. G., \& García, I. G. (2013a). Las pestes en la Antigüedad. Orígenes historiográficos. Revista de Historiografía, 13, 105-112.

Cravioto, E. G., \& García, I. G. (2013b). Una aproximación a las pestes y epidemias en la antigüedad. Espacio Tiempo y Forma. Serie II, Historia Antigua, 26, 63-82.

De Rezende, J. M. (1998). Epidemia, endemia, pandemia, epidemiologia. Revista de Patologia Tropica, 27(1). doi: https://doi.org/10.5216/rpt.v27i1.17199

Esparza, J. (2016). Epidemias y pandemias virales emergentes: ¿cuál será la próxima? Investigación clínica, 57(3), 231-235.

Galeano, D. (2009). Médicos y policías durante la epidemia de fiebre amarilla (Buenos Aires, 1871). Salud colectiva, 5, 107-120.

Giménez, A. G., \& Pardo, C. G. (2018). La peste (plaga) de Atenas. Revista de Investigación y Educación en Ciencias de la Salud, 3(2), 61-63. doi: https://doi.org/10.37536/RIECS.2018.3.2.90

González Valdés, L. M., Casanova Moreno, M. D. L. C., \& Pérez Labrador, J. (2011). Cólera: historia y actualidad. Revista de Ciencias Médicas de Pinar del Río, 15(4), 280-294.

González-Hernández, M., Sánchez-Paya, J., Ros Vivancos, C., Navarro Gracia, J. F., Martínez Vicente, M., Tenza Iglesias, I., \& González Torga, A. (2017). El tifus epidémico. Prevención y tratamiento a través de la historia. Medicina Preventiva, 22(3), 37-44.

Grmek, M. D. (1992). Historia del SIDA. Buenos Aires: Siglo XXI.

Guerrero, E. T., Martínez, F. V., Diéguez, C. E. A., Arrazola, J., \& Guzmán, R. A. (2012). Lepra. Clasificación y cuadro clínico. Dermatología Revista Mexicana, 56(1), 47-54.

Hoffman, L. (1987). Fundamentos de la terapia familiar. Buenos Aires: Fondo de Cultura Económico.

Huguet Pané, G. (2020). Grandes pandemias de la historia. Recuperado de www.Historia.nationalgeographic.com.es

Infosalus (2020). Breve historia de las pandemias globales: cómo hemos luchado contra los mayores asesinos. Infosalus [Internet]. Recuperado de https://m.infosalus.com/saludinvestigacion/noticia-breve-historiapandemias-globales-hemos-lucha-do-contra-mayoresasesinos-20200322075937.html 
Jáuregui-Lobera, I. (2017). Navegación e historia de la ciencia: escorbuto. Journal of Negative and No Positive Results, 2(9), 416-430. doi: https://doi.org/10.19230/jonnpr.1510

Leitner, R. M. C., Körte, C., Edo, D., \& Braga, M. E. (2007). Historia del tratamiento de la sífilis. Revista Argentina de Dermatología, 88(1), 6-19.

Marcone, A. (2002). Peste antonina. Testimonianze e interpretazioni. Rivista storica italiana, 114(3), 803-819.

Ortiz, R. (2020). La plaga de justiniano (541-542). Medicina, 42(2), 182-195.

Pereira, Á. \& Pérez, M. (2002). Epidemiología y tratamiento del paludismo. Offarm, 21(6), 110-114.

Pérez Abreu, M. R., Gómez Tejeda, J. J. \& Dieguez Guach, R. A. (2020). Características clínicoepidemiológicas de la COVID-19. Revista Habanera de Ciencias Médicas, 19(2).

Restrepo, B. N. (2004). Fiebre amarilla. CES medicina, 18(1), 69-82. doi: https://doi.org/10.21615/cesmedicina

Rius i Gibert, C. (2019). La peste a lo largo de la historia. Revista Enfermedades Emergentes, 18(3), 119-127.

Rizzi, M. (2004). Historia del escorbuto. Sociedad Uruguaya de Historia de la Medicina, 22, 288298.

Rodríguez, V. R. (2020). A propósito del SARS CoV 2/COVID 19 ¿Qué hemos aprendido de las pandemias? Revista avances en salud, 4(1), 6-10.

Ruiz-Patiño, A. (2020). La plaga antonina. Medicina, 42(2), 175-181.

Sánchez Lera, R. M., \& Pérez Vázquez, I. A. (2014). Cólera: historia de un gran flagelo de la humanidad. Humanidades Médicas, 14(2), 547-569.

Suárez, R. E. G., \& Lombardi, C. (1997). Estimado de prevalência de lepra. Hansen int, 22(2), 3135.

Swenson, R. M. (1989). Las epidemias, la historia y el SIDA. Política Exterior, 3(9), 229-237. doi: https://doi.org/10.2307/20642802

Testa, D. E. (2012). La lucha contra la poliomielitis: una alianza médico-social, Buenos Aires, 1943. Salud colectiva, 8, 299-314.

Trilla, A. (2020). Un mundo, una salud: la epidemia por el nuevo coronavirus COVID-19. Medicina Clínica, 154(5), 175.

Villamil Jiménez, L. C. (2013). Epidemias y pandemias: una realidad para el siglo XXI. Un mundo y una salud. Revista Lasallista de Investigación, 10(1), 7-8.

Contribución de los autores: a) Concepción y diseño del trabajo; b) Adquisición de datos; c) Análisis e interpretación de datos; d) Redacción del manuscrito; e) revisión crítica del manuscrito.

M. R. C. ha contribuido en a, b, c, d, e.

Editora científica responsable: Dra. Cecilia Cracco. 